\title{
Early childhood exposure to media violence: What parents and policymakers ought to know
}

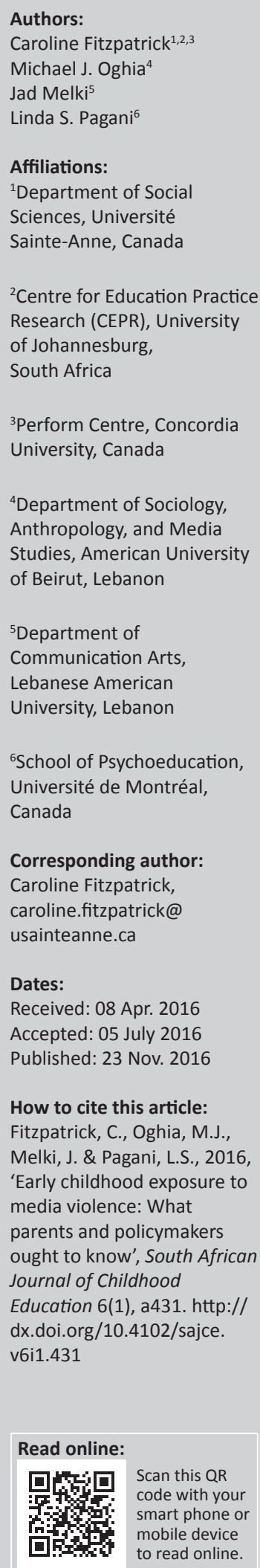

We review the state of evidence supporting a link between violent media exposure in preschoolaged children and subsequent well-being outcomes. We searched through four decades (1971-2011) of literature for enlightening details on the relationship between early exposure to media violence and health outcomes in later childhood and adolescence. Evidence suggests that preschool exposure may be linked to increased aggression and self-regulation problems. Results are discussed in the context of displacement, social cognitive and overstimulation theories. We recommend increasing efforts towards developing guidelines for families and professionals concerned with the well-being of children.

Over the past several decades, child development specialists have expressed concern over whether television violence, or media that depicts harmful intent expressed towards another person, poses a serious threat to the healthy development of children. Exposure to violent media by preschool-aged children especially has received little attention, although viewing habits in this age group have increased dramatically over the past decade, raising concerns for parents, paediatricians and researchers (Common Sense Media \& Rideout 2011; Sigman 2012). Some research suggests that the effects of media violence on child well-being are negligible. For example, a meta-analytic review of 25 published studies found the effects of violent media on aggressive behaviour to be modest at best (Ferguson \& Kilburn 2009). However, this meta-analysis included studies on adults and children from several age groups. Some recent studies provide strong evidence that preschool-aged children who view violent television are more likely to behave aggressively (Christakis et al. 2013; Robertson, McAnally \& Hancox 2013; Verlinden et al. 2012). The aim of the present critical review was to examine the state of the evidence supporting a link between early childhood (2- to 6-year-olds) exposure to violent media and subsequent health and well-being outcomes.

We searched through several decades (1971-2013) of educational, psychological, sociological, psychiatric, paediatric and communication literatures. Only peer-reviewed studies that employed either randomised control group designs or strong correlational designs which control for important confounders, such as baseline aggression and family context, were retained.

\section{Preschool-aged children and television violence}

Prior research on the effect of viewing media violence has primarily examined aggressive outcomes in school-aged children and adolescents. Studies and meta-analyses have found that exposure to media violence can induce increases in aggressive and violent behaviour in these populations (for a meta-analysis, see Anderson \& Bushman 2001; for reviews, see Bushman \& Huesmann 2006; Paik \& Comstock 1994; Villani 2001). Furthermore, research suggests that adolescents who view more violent content are also at risk of increased fearfulness, anxiety and symptoms of emotional distress (Villani 2001).

The consequences of exposure to violent media are likely to vary according to a child's age and developmental stage. There is consensus amongst the scientific community that early experiences often matter more than those that occur later in life (Heckman 2006; Shonkoff \& Phillips 2000). In particular, child development specialists recognise that preschool years mark a sensitive period for social, cognitive and behavioural development. The science of brain development has shown that children display heightened sensitivity to environments and experiences during these formative years. In favourable conditions, when children benefit from high-quality education and caregiving experience, development is optimised. However, this period of environmental sensitivity can also lead to increased vulnerability to stressful experiences and environments. Consequently, an examination of the effects of viewing media violence in early childhood is warranted. 


\section{Context}

According to a study by the Kaiser Foundation, over $60 \%$ of American families have three or more television sets in their households (2007). Over $80 \%$ of families also subscribed to cable, which further increases viewing options for children. Furthermore, it is estimated that $83 \%$ of children aged 6 and younger are exposed to television on a typical day and two-thirds of children are exposed to television every day. In addition, for half the surveyed households, parents reported that a television was present in their child's bedroom. Finally, a study conducted by UNESCO (1999), which surveyed the viewing habits of children in 23 countries, also found that $93 \%$ of school-aged children spent more than half of their leisure time watching television.

More recent research suggests that children today are exposed to more screens than ever before, which can multiply viewing opportunities. For example, British children today will grow up with access to an average of five different types of screens, including smartphones, tablets and computers (Jago et al. 2011). Furthermore, in the United States, close to one-third of children aged 3 or younger have a television in their room (Common Sense Media \& Rideout 2011). Indeed, it is estimated that the typical child in an industrialised nation will spend an average of 3 years in front of screens before their seventh birthday (Sigman 2012).

In addition to spending much of their free time watching television, much of the content children view is likely to be violent. For example, the US National Television Violence Study (Federman 1995) surveyed general programming to assess the extent of violence on television. According to this study, $61 \%$ of programmes contained some form of violence. However, only a small number of programmes depicted long-term consequences for victims and perpetrators. Furthermore, in $71 \%$ of violent scenes, there was no expression of remorse on behalf of the perpetrator. Violence was associated with humour in $41 \%$ of cases. Lethal violence was common and frequently perpetrated by attractive characters. Other research has shown that in programmes specifically targeted at young viewers, as many as 25 violent acts can be observed per hour. Perhaps more concerning are recently noted increases in violent content in general programming, cartoons and blockbuster action films (Bushman et al. 2013; Yokota \& Thompson 2000). In this study, the researchers found that gun violence, in particular, has been increasing sharply over the past 50 years (Bushman et al. 2013). Taken together, these studies indicate that violent content is common even in mainstream programming to which young children are frequently exposed.

\section{Violent television and aggression}

Experimental studies with school-aged children provide compelling evidence of a causal relationship between violent media exposure and increased short-term risk of engaging in aggressive behaviour. In general, children randomly assigned to view violent content are more likely to use aggressive behaviour immediately afterwards when provided the opportunity. This is not the case for children randomly assigned to view non-violent programmes (Paik \& Comstock 1994). In a classic study, 396 eight- to tenyear-old American boys were randomly assigned to view either violent or non-violent content before playing a game of hockey (Josephson 1987). Observers who were unaware which child had watched violent or non-violent content were asked to record aggressive behaviours (hitting, elbowing or shoving another player to the ground) during the game. Boys who viewed the violent programme engaged in more acts of physical aggression during the game. To remind the boys of the violent film they had viewed previously, during some of the games, the referee carried a walkie-talkie, as had one of the characters in the film. This was intended to prime aggressive behaviour. Interestingly, boys who had been rated by their teachers as initially high in aggression, who were then cued by the walkie-talkie, committed the highest number of aggressive acts in this sample.

Experimental research involving younger preschool children has been less conclusive in demonstrating an increased shortterm risk of engaging in aggressive behaviour following exposure to violent media. For example, in a systematic review of the literature, Thakkar, Garrison and Christakis (2006) found that only one out of six studies provided evidence for the effect of violent television exposure on short-term aggression. Furthermore, in this study, the effects of violent televiewing on short-term aggression were observed only for children who were initially more aggressive (Steuer, Applefield \& Smith 1971).

Longitudinal studies have provided more compelling evidence of an association between naturally occurring differences in exposure to television violence and the development of aggression. In one prospective study, Christakis and Zimmerman (2007) examined children exposed to violent media between the ages of 2 and 5 years. They found that exposed children were four times more likely to score in the top 15th percentile on an assessment of antisocial behaviour at age 8 . These results remained significant after controlling for the potentially confounding effect of pre-existing child aggression, parental socio-demographic characteristics and overall screen time. Similarly, another longitudinal study conducted with French Canadian children from the province of Quebec found associations between exposure to violent television programmes and movies at the age of 4 and later teacher-rated antisocial behaviours at age 8 (Fitzpatrick, Barnett \& Pagani 2012). These analyses also controlled for baseline child aggression, overall screen time and socioeconomic factors.

Huesmann et al. (2003) assessed exposure to television violence at age 6. Children were followed up 15 years later. 
Remarkably, significant long-term associations were found between childhood exposure and later aggressive behaviour for both the men and women in this sample. That is, men and women who had been exposed to higher amounts of violent content during early childhood were more likely to have engaged in serious forms of aggression by adulthood. Furthermore, even though certain gender differences were observed in the pattern of results, high levels of exposure were associated with a higher than expected frequency of engaging in criminal behaviour, spousal abuse and dangerous driving for both men and women (Huesmann et al. 2003).

Finally, more recently, a longitudinal study of children in New Zealand found that children who watched more television between the ages of 5 and 15 were more likely to show antisocial behaviour, as measured by multiple indicators (Robertson et al. 2013). For example, although violent television was not assessed specifically, more exposure to television during childhood predicted criminal convictions, being diagnosed with antisocial personality disorder and having an aggressive personality. Results were similar across genders, and were not explained by children's pre-existing levels of aggression, socio-economic status, intelligence quotient or parenting characteristics.

\section{Self-regulation}

Some studies suggest that watching fast-paced programmes that contain high levels of violence can have negative consequences on child self-regulation (Friedrich \& HustonStein 1973). For example, in one study, children were randomly assigned to view $1 \mathrm{~h}$ of either the Mighty Morphin Power Rangers or Mister Rogers. Children who viewed the Power Rangers, but not the control children, were more likely to show lower levels of concentration and sustained attention whilst completing a task immediately following the viewing (Geist \& Gibson 2000).

In another study, the researchers examined child exposure to violent content in a sample of 1800 Canadian children at age 4 . Children were followed up at the age of 8 . After taking into account family background characteristics (e.g. income, presence of violence in the home and parental aggression) and child baseline aggression and behaviour problems, it was found that children who watched more violent content exhibited more aggressive behaviour and attention problems (Fitzpatrick et al. 2012).

Experimental evidence also suggests that violent media may be causally linked to poor attention. In one experiment, children were randomly assigned to watch either a fast-paced cartoon that contained lots of action and violence or an educational cartoon. Following a brief exposure of $9 \mathrm{~min}$, children exposed to the fast-paced cartoon performed worse on a task measuring executive functions, which are skills that allow children to exercise control over thinking and attention (Lillard \& Peterson 2011).

\section{Theoretical explanations Social learning}

According to social cognitive theories, observing acts of violence can influence the development of mental models, or scripts, regarding how to behave and what to expect from one's social context (Kirsh 2011; Krahé et al. 2011). The perpetration of violent crimes and the use of aggression as a strategy to solve problems are the central focus in many television programmes. As a result, exposure to violent television may lead children to develop perceptions of their world as overly unsafe and dangerous. If perceptions of the 'world as hostile' persist, children risk developing a 'mean world syndrome', which can then predispose them to reacting aggressively towards ambiguous situations (Carnagey, Anderson \& Bushman 2007; Huesmann 2007; Media Education Foundation 2010).

The process of observational learning, which occurs during exposure to violent media, is also likely to be amplified by two factors. Firstly, attractive or heroic protagonists generally commit acts of violence in the media. Secondly, high levels of physiological arousal and stress occur during exposure, which can amplify children's risk of paying attention to, encoding and eventually imitating behaviours modelled in the media (Bandura 1986; Christakis 2009).

Finally, children exposed to violent media may also become desensitised to its arousing effect. Over the long term, this can lead to decreased sensitivity for victims of aggression (Huesmann \& Taylor 2006). As a result, overexposed children may be better able to plan and perform proactive acts of aggression whilst experiencing minimal levels of negative arousal.

Developmental perspectives are useful for explaining some of the discrepancies between experimental and longitudinal studies. More immediate increases in aggressive behaviour following the observation of media violence depend primarily on the priming of previously learned behavioural scripts (Anderson \& Carnagey 2014). Nevertheless, the development of scripts and schemas requires repeated exposure over time. As such, children may not show immediate priming effects to violence until later childhood or adolescence by which point they are likely to have developed cognitions that support aggressive behaviour. A meta-analysis of children and adolescents supports the hypothesis that short-term effects of media violence on behaviour are more likely to be observed in older children and adults than in very young children (Bushman \& Huesmann 2006). Interestingly, very young children who show greater predispositions to aggressive behaviour do show a short-term increase in aggressive behaviour following exposure to violent television content. Much like children who view lots of media violence over childhood, highly aggressive preschoolers may have come to develop scripts and cognitions that are more favourable to reacting aggressively during interpersonal interactions. These children may, in turn, be more prone to priming effects during exposure to violent media. 


\section{Overstimulation or overtaxing of cognitive resources}

The characteristics of violent television shows and movies include adrenaline-inducing action sequences, quick scene changes and captivating special effects (Christakis 2009).

Christakis (2009) has also found longitudinally that excessive exposure to fast-paced programming may lead children to eventually view real life as boring by comparison. In particular, this disposition may manifest itself in the classroom where children are often asked to persist on challenging tasks in the face of boredom or mental fatigue.

Exposure to scenes of violence which are overwhelming for young brains may also exercise their influence through an effect on executive functions. Executive functions are important not only for attention control but also for behavioural and emotional regulation and social reasoning. For example, children with poor executive function often have more difficulty inhibiting an impulsive aggressive reaction long enough to select a more reasonable nonaggressive course of action.

\section{Limitations}

Several limitations of this review merit discussion. Firstly, the observed effects seem inconsistent across genders. For this reason, further research should address which factors (i.e. biological, developmental or cultural) play a role in explaining gender differences in response to violent television exposure. Secondly, in this review, we only systematically reviewed key studies published over recent decades. As such, our conclusions are not based on an exhaustive metaanalysis of all available research. Finally, it was not possible to assess from the reviewed studies whether early childhood exposure to violent media may influence additional child health outcomes.

As pointed out by prior critiques (Ferguson \& Kilburn 2009), the magnitude of the effects linking violent television to aggression is typically small. Regardless, there is a consensus that even small effects represent a concern from a public health perspective (Browne \& Hamilton-Giachritsis 2005). Small effect sizes are multiplied when exposure is widespread across the population. For example, the strength of the relationship between violent media exposure and risk of engaging in aggressive behaviour is in the same range as the strength of the association between condom use and risk of contracting sexually transmitted infections or smoking and risk of contracting lung cancer (Paik \& Comstock 1994). Therefore, because they occasion immeasurable human costs, identifying preventable predictors of violence and aggression, regardless of their effect size, remains an important task.

\section{Future research}

In this review, we did not assess whether violent video game playing during the preschool years is related to later aggressive behaviours. A review of experimental studies conducted with older children suggests that playing violent video games can lead to increases in aggressive behaviour and the incidence of aggression-related thoughts in young boys and girls. Exposure was also found to decrease children's tendency to display prosocial behaviour (Anderson \& Bushman 2001). Because video game use remains a popular pastime for youth, it remains important to better understand its potential influence on later child development.

Even though recent research on exposure to media violence in older children has explored a wider range of child adjustment and health indicators, these outcomes remain to be addressed in preschool-aged children. Some research suggests that much like physical violence, viewing indirect or relational aggression such as the use of social exclusion, spreading rumours or verbal insults may foster aggressive behaviour in children. In one example, children aged 11-14 were randomly assigned to view content that depicts physical, relational or no aggression (Coyne, Archer \& Eslea 2004). Children exposed to both types of aggressive content showed more indirect aggression towards a confederate following the experiment. Future research should examine whether early exposure to relational or indirect aggression during the preschool years predicts aggression in later childhood and emerging adulthood.

Some children may also be at risk of developing emotional distress symptoms as a result of their exposure to scenes of violence. Firstly, perpetrators of aggression are more likely to experience internalising problems (Card et al. 2008). In addition, much like witnessing real-life violence, some evidence suggests that exposure to violent media programming is associated with symptoms of anxiety and depression in both children and adolescents (Dobkin et al. 1995; Friedrich \& Stein 1973; Singer et al. 1995). Some research has shown a relationship between adolescent consumption of violent media and video games and the development of internalising problems (Singer et al. 1995). Little research has addressed this possible outcome in preschool children. However, given that very young children dispose of less effective personal coping and self-regulation strategies, they may be especially vulnerable to the fear-inducing consequences of violent media. There are some data which suggest that exposure to violent television and movies at age 4 is associated with long-term risk for later emotional distress (Fitzpatrick et al. 2012).

Adding to the estimated health burden of violent television exposure, aggressive children are also likely to underperform academically and show poor social adaptation (Campbell et al. 2006; Caprara et al. 2000; Chen et al. 2010). One reason for this is that children who are aggressive are less likely to be popular amongst peers and may be perceived more 
negatively by teachers. Social rejection may also contribute to feelings of emotional distress and depression, which may further undermine self-esteem, achievement and motivation to learn (Gest et al. 2008). There is some correlational evidence linking television and movie violence exposure during the preschool years to the development of academic problems by the age of 8 (Fitzpatrick et al. 2012).

Finally, violent music videos, programmes and movies are also effective vehicles of racial and gender-based stereotypes. In music videos and films that involve frequent scenes of action and violence, males are perpetrators of violence in more than $75 \%$ of cases, and females are disproportionately portrayed as victims. In addition, African American males represent approximately $12 \%$ of the population of the United States; however, they are presented as perpetrators of violence in more than $25 \%$ of television and music videos (Browne \& Hamilton-Giachritsis 2005). Early childhood exposure to media content which presents high levels of violence is therefore likely to foster additional risks for developing negative gender and racial stereotypes. Such stereotypes may then play a role in the perpetuation of social and institutional inequalities on the basis of gender and ethnicity.

\section{Conclusion}

Although the majority of parents endorse the idea that media violence contributes to aggressive behaviour in children, only $43 \%$ of parents actively monitor and intervene to prevent their child from viewing unsuitable programmes (Cheng et al. 2004). The industry is required to regulate and rate the appropriateness of television and movie content for children. Nevertheless, parents tend to disagree with these ratings. That is, much of the content rated as suitable for young viewers by the film and television industries is perceived by parents as inappropriate for children because of high levels of violent or sexual content (Gentile et al. 2011).

Parents are important gatekeepers of children's access to media. To reduce aggression and improve child health within our communities, it remains important for parents to be sensitised about the potential harmful effects of media violence on their children (Cheng et al. 2004). Upon viewing disturbing scenes, parents can help minimise the negative effects on their children by discussing the violence (Christakis 2009). Parents can play an important role in controlling children's access to violent programmes and video games. For example, Christakis et al. (2013) have recently developed an intervention to reduce child exposure to media violence by using a cognitive behavioural therapy approach with parents to help them substitute prosocial and educational programmes for violent content. Parents were instructed to modify the content of their child's viewing, but not to reduce overall screen time. Children whose parents were randomly assigned to the media training intervention showed short-term reductions in externalising behaviour and more sustained improvements in social competence.
The programme was most effective for disadvantaged boys, a group particularly vulnerable to media violence. Combined with efforts to reduce overall screen time, modifying child media diets therefore represents a promising strategy for preventing the development of antisocial behaviour across the population (Christakis et al. 2013). In summary, a public health approach to reducing the harmful effects of violent media on children strongly depends on the active involvement of parents.

Our review suggests that exposure to violent media during the preschool years poses a reliable but small long-term risk for engaging in aggressive behaviour in later childhood and adulthood. There is also some concern that exposure to media violence may contribute to self-regulation and attention problems. Despite relatively small effect sizes across studies, we also argue that because of its association with health problems and high-stake social problems such as habituation to aggression, exposing young children to violent media represents a costly social problem.

\section{Acknowledgements Competing interests}

The authors declare that they have no financial or personal relationships which may have inappropriately influenced them in writing this article.

\section{Authors' contributions}

C.F. and L.P. were project leaders and drafted the manuscript. M.O. and J.M. made conceptual contributions and helped review and edit the manuscript.

\section{References}

Anderson, C. \& Bushman, B., 2001, 'Effects of violent video games on aggressive behavior, aggressive cognition, aggressive affect, physiological arousal, and prosocial behavior: A meta-analytic review of the scientific literature', Psychological Science 12(5), 353. http://dx.doi.org/10.1111/1467-9280.00366

Anderson, C.A. \& Carnagey, N.L., 2014, 'The role of theory in the study of media violence: The General Aggression Model', in D.A. Gentile (ed.), Media violence and children, 2nd edn., pp. 103-133, Praeger, Westport, CT.

Bandura, A., 1986, Social foundations of thought and action: A social cognitive theory, Prentice Hall, Englewood Cliffs, NJ.

Browne, K.D. \& Hamilton-Giachritsis, C., 2005, 'The influence of violent media on children and adolescents: A public-health approach', The Lancet 365(9460), 702-710. http://dx.doi.org/10.1016/S0140-6736(05)70938-7

Bushman, B. \& Huesmann, L., 2006, 'Short-term and long-term effects of violent media on aggression in children and adults', Archives of Pediatrics \& Adolescent Medicine 160(4), 348. http://dx.doi.org/10.1001/archpedi.160.4.348

Bushman, B.J., Jamieson, P.E., Weitz, I. \& Romer, D., 2013, 'Gun violence trends in movies', Pediatrics 132(6), 1014-1018.

Campbell, S., Spieker, S., Burchinal, M. \& Poe, M., 2006, 'Trajectories of aggression from toddlerhood to age 9 predict academic and social functioning through age 12', Journal of Child Psychology and Psychiatry 47(8), 791-800. http://dx.doi. org/10.1111/j.1469-7610.2006.01636.x

Caprara, G., Barbaranelli, C., Pastorelli, C., Bandura, A. \& Zimbardo, P., 2000, 'Prosocial foundations of children's academic achievement', Psychological Science 11(4), 302. http://dx.doi.org/10.1111/1467-9280.00260

Card, N., Stucky, B., Sawalani, G. \& Little, T., 2008, 'Direct and indirect aggression during childhood and adolescence: A meta-analytic review of gender differences, intercorrelations, and relations to maladjustment', Child Development 79(5), 1185-1229. http://dx.doi.org/10.1111/j.1467-8624.2008.01184.x

Carnagey, N.L., Anderson, C.A. \& Bushman, B.J., 2007, 'The effect of video game violence on physiological desensitization to real-life violence', Journal of Experimental Social Psychology 43(3), 489-496. 
Chen, X., Huang, X., Chang, L., Wang, L. \& Li, D., 2010, 'Aggression, social competence, and academic achievement in Chinese children: A 5-year longitudinal study' and academic achievement in Chinese children: A 5-year longitudinal study', Development and Psych
S0954579410000295

Cheng, T.L., Brenner, R.A., Wright, J.L., Sachs, H.C., Moyer, P. \& Rao, M.R., 2004 'Children's violent television viewing: Are parents monitoring?', Pediatrics 114(1), 94. http://dx.doi.org/10.1542/peds.114.1.94

Christakis, D.A., 2009, 'The effects of infant media usage: What do we know and what should we learn?', Acta Paediatrica 98(1), 8-16. http://dx.doi.org/10.1111/j.16512227.2008.01027.x

Christakis, D.A., Garrison, M.M., Herrenkohl, T., Haggerty, K., Rivara, F.P., Zhou, C. et al., 2013, 'Modifying media content for preschool children: A randomized controlled trial', Pediatrics 131(3), 431-438.

Christakis, D.A. \& Zimmerman, F.J., 2007, 'Violent television viewing during preschoo is associated with antisocial behavior during school age', Pediatrics 120(5), 993. http://dx.doi.org/10.1542/peds.2006-3244

Coyne, S.M., Archer, J. \& Eslea, M., 2004, 'Cruel intentions on television and in real life: Can viewing indirect aggression increase viewers' subsequent indirect aggression?', Journal of Experimental Child Psychology 88(3), 234-253. http:// dx.doi.org/10.1016/j.jecp.2004.03.001

Dobkin, P.L., Tremblay, R.E., Masse, L.C. \& Vitaro, F., 1995, 'Individual and peer characteristics in predicting boys' early onset of substance abuse: A seven-year longitudinal study', Child Development 1198-1214. http://dx.doi.org/10.2307/1131807

Earp, J., 2010, The Mean World Syndrome: Media Violence \& the Cultivation of Fear, Media Education Foundation.

Federman, J. (ed.), 1995, National television violence study: Executive summary, University of California, Center for Communication and Social Policy, Berkeley, CA.

Ferguson, C.J. \& Kilburn, J., 2009, 'The public health risk of media violence: A meta analytic review', Journal of Pediatrics 154, 759-763. http://dx.doi.org/10.1016/j. jpeds.2008.11.033

Fitzpatrick, C., Barnett, T. \& Pagani, L.S., 2012, 'Early exposure to media violence and later child adjustment', Journal of Developmental \& Behavioral Pediatrics 33(4) 291-297. http://dx.doi.org/10.1097/DBP.0b013e31824eaab3

Friedrich, L. \& Stein, A., 1973, 'Aggressive and prosocial television programs and the natural behavior of preschool children', Monographs of the Society for Research in Child Development 38(4), 1-64. http://dx.doi.org/10.2307/1165725

Geist, E.A. \& Gibson, M., 2000, 'The effect of network and public television programs on four and five year olds ability to attend to educational tasks', Journal of Instructional Psychology 27(4), 250.

Gentile, D.A., Maier, J.A., Hasson, M.R. \& Lopez de Bonetti, B., 2011, 'Parents' evaluation of media ratings a decade after the television ratings were introduced', Pediatrics 128, 36-44. http://dx.doi.org/10.1542/peds.2010-3026

Gest, S., Rulison, K., Davidson, A. \& Welsh, J., 2008, 'A reputation for success (or failure): The association of peer academic reputations with academic self-concept effort, and performance across the upper elementary grades', Developmental Psychology 44(3), 625-635. http://dx.doi.org/10.1037/0012-1649.44.3.625

Heckman, J.J., 2006, 'Skill formation and the economics of investing in disadvantaged children', Science, 312(5782), 1900-1902. http://dx.doi.org/10.1126/science.1128898

Huesmann, L. \& Taylor, L., 2006, 'The role of media violence in violent behavior', Annual Review of Public Health 27, 393-415. http://dx.doi.org/10.1146/annurev. publhealth.26.021304.144640
Huesmann, L.R., Moise-Titus, J., Podolski, C.L. \& Eron, L.D., 2003, 'Longitudinal relations between children's exposure to TV violence and their aggressive and violent behavior in young adulthood: 1977-1992', Developmental Psychology 39(2), 201-221. http://dx.doi.org/10.1037/0012-1649.39.2.201

Jago, R., Sebire, S.J., Gorely, T., Cillero, I.H. \& Biddle, S.J., 2011, '"I'm on it 24/7 at the moment": A qualitative examination of multi-screen viewing behaviours among UK 10-11 year olds', International Journal of Behavioral Nutrition and Physical Activity 8, 85. http://dx.doi.org/10.1186/1479-5868-8-85

Josephson, W., 1987, 'Television violence and children's aggression: Testing the priming, social script, and disinhibition predictions', Journal of Personality and Social Psychology 53(5), 882-890. http://dx.doi.org/10.1037/0022-3514.53.5.882

Kirsh, S.J., 2011, Children, adolescents, and media violence: A critical look at the research, Sage.

Krahé, B., Möller, I., Huesmann, L.R., Kirwil, L., Felber, J. \& Berger, A., 2011, 'Desensitization to media violence: Links with habitual media violence exposure, aggressive cognitions, and aggressive behavior', Journal of Personality and Social Psychology 100, 630. http://dx.doi.org/10.1037/a0021711

Lillard, A.S. \& Peterson, J., 2011, 'The immediate impact of different types of television on young children's executive function', Pediatrics 128(4), 644-649. http://dx.doi. org/10.1542/peds.2010-1919

Paik, H. \& Comstock, G., 1994, 'The effects of television violence on antisocial behavior: A meta-analysis1', Communication Research 21, 516-546. http://dx.doi. org/10.1177/009365094021004004

Rideout, V., 2016, Zero to eight: children's media use in America. San Francisco: Common Sense Media, viewed 03 Dec. 2011, from http://www. commonsensemedia.org/sites/default/files/research/zerotoeightfinal2011. pdf

Robertson, L.A., McAnally, H.M. \& Hancox, R.J., 2013, 'Childhood and adolescent television viewing and antisocial behavior in early adulthood', Pediatrics 131(3), 439-446. http://dx.doi.org/10.1542/peds.2012-1582

Shonkoff, J. \& Phillips, D., 2000, From neurons to neighbourhoods: The science of early childhood development, National Academy Press, Washington, DC.

Sigman, A., 2012, 'Time for a view on screen time', Archives of Disease in Childhood. http://dx.doi.org/10.1136/archdischild-2012-302196

Singer, M., Anglin, T., Song, L. \& Lunghofer, L., 1995, 'Adolescents' exposure to violence and associated symptoms of psychological trauma', JAMA 273, 477-482. http:// dx.doi.org/10.1001/jama.1995.03520300051036

Steuer, F.B., Applefield, J.M. \& Smith, R., 1971, 'Televised aggression and the interpersonal aggression of preschool children* 1', Journal of Experimental Child Psychology 11(3), 442-447. http://dx.doi.org/10.1016/0022-0965(71)90048-8

Thakkar, R.R., Garrison, M.M. \& Christakis, D.A., 2006, 'A systematic review for the effects of television viewing by infants and preschoolers', Pediatrics 118(5), 2025-2031.

Verlinden, M., Tiemeier, H., Hudziak, J.J., Jaddoe, V.W.V., Raat, H., Guxens, M. et al., 2012, 'Television viewing and externalizing problems in preschool children the Generation R StudyTelevision viewing and externalizing problems', Archives of Pediatrics \& Adolescent Medicine 166(10), 919-925. http://dx.doi.org/10.1001/ archpediatrics.2012.653

Villani, S., 2001, 'Impact of media on children and adolescents: A 10-year review of the research', Journal of Amer Academy of Child \& Adolescent Psychiatry 40 392-401. http://dx.doi.org/10.1097/00004583-200104000-00007

Yokota, F. \& Thompson, K.M., 2000, 'Violence in G-rated animated films', JAMA 283(20), 2716-2720. 